\title{
CuAderno De Tyler DuRden
}

\author{
Mijail Lamas \\ How much can you really know yourself if you 've \\ never been in a fight? \\ Tyler Durden \\ Nunca conheci quem tivesse levado porrada. \\ Todos os meus conhecidos têm sido campeões \\ em tudo. \\ Fernando Pessoa
}

\section{HOY NO TENGO NECESIDAD DE FINGIR \\ QUE ELIJO LA VIDA QUE ME TOCA}

10 años después de mi primer rock n'roll

me sigo tropezando con la misma rocka

que mueve el culo frente a la $\mathrm{t} v$.

Suenan bocinas

y todos al correr golpean sus cráneos entre sí, hay sudor y una garganta que grita,

un cuerpo que se toca, unas manos que responden, mi aliento en la inflamable canción de la cerveza.

Esta es la verdadera fiesta

donde nada se pide y todo se toma, donde no hay culpa ni pecado, porque antes de volver en el camión derrotado de los derrotados, antes del The End de la canción voy a gritar

y masticar mi rabia. 
He nacido oscuro por el resto del día $\mathrm{y}$ tras una nube el ojo de dios guarda silencio. Soy la sombra de todos los rostros, dependiente de tiempo completo, maestro por horas de miseria, desempleado frente a las marquesinas.

Hoy llevo un dolor de piedra entre las manos.

Lejos de toda caridad soy profeta y apóstol jubilado de la fe en mí mismo, oficio los silencios de la página.

Soy héroe, peatón del instante y la sorpresa. Aquí guardo la plegaria del azar y una sensación de sed como aguja en las palabras. Hoy no tengo necesidad de fingir que elijo la vida que me toca

Siempre tengo el deseo de estar en otra parte.

Apenas yo consigo llegar a mi destino,

me invade la inexplicable necesidad de huir.

Más de una hora de quietud

en un mismo lugar es excesivo.

Tengo que salir,

caminar,

cansar mis pies,

ser siempre un pasajero,

detenerme por el sueño apenas.

Hoy dejo claro que me es primordial el viaje, la azarosa aventura del cuarto a la cocina, de la cocina a la sala, para desordenarlo todo; salir a la calle, 
tomar con prisa este café, escribir este poema apresurado, pasar un momento por todo:

la derrota, la risa, la costumbre, el perdón siempre insuficiente, el destino plural, el vasto guiño con el que la muerte espera decir su parlamento.

Caminar es necesario, danzar las horas, trazar mil y un caminos para no acostumbrarse a nada, no conformarse con todo.

Sólo la vida podrá cansar nuestra obstinación y agotar su presupuesto.

La sola inmovilidad me aterra. 